\title{
FORMAÇÃO DE PROFESSORES E HERMENÊUTICA: REFLEXÕES PARA O CAMPO DA EDUCAÇÃO FÍSICA... ${ }^{1}$
}

\author{
Angelica Madela \\ Universidade Comunitária da Região de Chapecó, Chapecó, Santa Catarina, Brasil \\ Jamile Dal-Cin \\ Universidade Comunitária da Região de Chapecó, Chapecó, Santa Catarina, Brasil \\ Sara Both Rezende \\ Universidade Comunitária da Região de Chapecó, Chapecó, Santa Catarina, Brasil \\ Ricardo Rezer \\ Universidade Comunitária da Região de Chapecó, Chapecó, Santa Catarina, Brasil
}

\begin{abstract}
Resumo
Este texto tem por objetivo fazer algumas aproximações entre a formação de professores e a hermenêutica, a fim de promover uma reflexão no campo da Educação Física (EF). Para tal, inicialmente, apresentamos uma breve compreensão de hermenêutica. Em seguida, abordamos a questão da hermenêutica no processo de formação de professores e especificamente no campo da EF. Concluímos que levar a sério essa discussão na formação de professores de EF representa um esforço complexo, na medida em que abrimos mão do conforto dos dogmas e pensamentos preconcebidos, e mergulhamos na possibilidade de inflexão sobre os diferentes conhecimentos que podem constituir um processo de formação docente no campo da EF.
\end{abstract}

Palavras-chave: Educação Física. Hermenêutica. Educação Superior.

\section{Introdução}

Este texto tem por objetivo fazer algumas aproximações entre a formação de professores e a hermenêutica, a fim de promover uma reflexão no campo da Educação Física (EF). O texto se baseia em dois argumentos centrais:

a) o processo de formação de professores necessita incorporar um sentido formativo amplo nas suas práticas educativas, ultrapassando os limites das finalidades técnicas - dimensão imprescindível, porém, insuficiente em um processo de formação docente que se pretenda ampliado;

b) temos de aprender a reconhecer a pluralidade política e epistemológica do campo da EF como possibilidade para enriquecer propostas de formação de professores na área. Para tal, mais do que "optar" por uma ou algumas abordagens como centralidade para o processo de formação, entendemos que carecemos de uma cultura política e epistemológica que possibilita aprendermos mais e melhor sobre a diversidade política e epistemológica do próprio campo ${ }^{2}$.

\footnotetext{
${ }^{1} \mathrm{O}$ presente trabalho contou com apoio da FAPESC/CAPES para sua realização.

2 Não desconsideramos que, em meio a diferentes "Educações Físicas", existem diferentes projetos de EF e de sociedade. Porém, isso não resulta na necessidade de um "discurso vencedor", que anule os demais, e represente a "verdadeira" EF. Pelo contrário, em meio à diversidade política e epistemológica, encontramos uma fecundi- 
Nessa direção, uma responsabilidade da formação de professores é apresentar de forma crítica o diálogo interno da EF na contemporaneidade, permitindo aos futuros professores um trânsito menos ingênuo e mais articulado à conjuntura política e epistemológica desse campo.

Para dar conta do objetivo proposto, apresentaremos algumas reflexões que permitam aprofundar essa discussão no campo da EF. Visualizamos no diálogo uma possibilidade de construção de novos sentidos e, através de um esforço hermenêutico, a possibilidade de conviver com outras maneiras de interpretar os conhecimentos relacionados à EF. Por fim, fazemos uma reflexão acerca da hermenêutica no contexto específico da EF, compreendendo esse referencial como uma possibilidade de um olhar mais elaborado e alargado acerca do processo de formação de professores nesse campo.

\section{Hermenêutica e formação de professores}

As aproximações entre hermenêutica e o campo da EF, conforme apontado por Almeida et al. (2012), ainda são bastante recentes. Segundo os autores, não existe, na área, uma tradição de estudos propriamente hermenêuticos. "Só recentemente alguns pesquisadores têm feito esforços inéditos nessa direção, com destaque para Fensterseifer $(2009,2010)$ e Rezer (2010)." Assim sendo, apresentaremos primeiramente uma breve reflexão sobre a compreensão de hermenêutica que assumimos no desenvolvimento de diferentes trabalhos. Mais do que uma "definição de termos", pretendemos situar o referencial de fundo com o qual iremos abordar o campo da EF, especialmente neste caso, no que se refere à formação de professores $^{3}$.

De origem grega, hermenêutica se origina do verbo hermeneuein, significando "interpretar" - já no substantivo, significa "interpretação". Segundo Ruedell (2005, p.224), o uso desta palavra remete à mitologia grega, mais precisamente ao deus Hermes, conhecido como deus mensageiro. "Hermes associa-se à transmutação, à transformação de tudo o que está acima da compreensão humana, tornando-o acessível à inteligência humana" ${ }^{4}$. A partir disto, a hermenêutica representa um esforço para tornar compreensível o que é distante e obscuro um esforço que, sobremaneira, interessa a um processo de formação de professores de EF, especialmente se considerarmos o quadro de diversidade que compõem o campo, como referido anteriormente.

Corroborando Ruedell, Hermann (2002 p.24) afirma que "a hermenêutica carrega consigo a ideia de tornar explícito o implícito, de descobrir a mensagem, de torná-la compreensível". Ruedell (2005) afirma que a hermenêutica não é apenas "interpretar por interpretar", pois também se relaciona ao sentido de anunciar, traduzir e explicar - aqui a noção de sentido adquire caráter de extrema importância (ou, como se refere Berticelli (2004), jamais haverá compreensão onde não se descobrir o sentido). Para Palmer (2011), esses verbos podem ser expressos por interpretar - mas, se cada um tem um sentido próprio e relevante do termo "interpretação", apresenta-se uma questão que nos interessa, a produção de sentidos em comum como possibilidade de ensinar e de aprender no mundo comum. Nesse caso, a formação de

dade para a construção de um campo complexo que pode alçar isso à condição de importante lastro para processos de formação de professores.

${ }^{3}$ Temos clareza das discussões presentes no campo da EF relacionadas às divergências acerca das expressões professor e profissional. Porém, não iremos abordar esse debate, devido a seu escopo. Trabalhamos com a ideia de que um egresso de um curso de formação inicial em EF se trata de um professor, que pode atuar em diferentes contextos de docência. Assim, entendemos que uma intervenção no campo da EF deveria ser sempre uma intervenção pedagógica, em qualquer contexto de atuação.

${ }^{4}$ Em termos mitológicos, também poderíamos remeter as raízes do termo à imagem do anjo Gabriel, que anunciou o Salvador para os cristãos. A comparação entre os dois se deve ao fato de ambos serem mensageiros, porém, de mensagens diferentes. Neste caso, Hermes seria o mensageiro a que se refere a hermenêutica, deus pagão, e Gabriel faz parte da narrativa religioso-teológica cristã. 
professores passa pelo sentido da formação ampliada, pelo sentido do compromisso de ser professor, bem como pelo sentido do conhecimento na edificação de uma trajetória docente.

Porém, os referenciais da hermenêutica não são consensuais per se. Há significativa divergência acerca do sentido da própria hermenêutica contemporaneamente. Em muitos casos, há uma subvalorização do potencial hermenêutico, como se ela representasse, quando muito, um referencial metodológico. Concordando com Gadamer (2007), a hermenêutica representa bem mais que uma metodologia, pois está pautada no diálogo e nos desafia a reconhecer o outro como parceiro importante no caminho da busca por esse saber. Ao mesmo tempo, nos faz refletir que "o processo de compreender revela-nos a primazia de um acontecer, ao qual o indivíduo - embora dele sendo parte necessária - não pode impor, unilateralmente, seu ponto de vista" (FLICKINGER, 2010, p.114).

O esforço hermenêutico, a partir da ampliação de nossa compreensão sobre ele, amplia também as relações e as possibilidades de interpretar e compreender os fenômenos que vivenciamos no processo de intervenção pedagógica. Ou seja, possibilita a construção de espaços para a aproximação entre diferentes, através do diálogo que permita aos sujeitos envolvidos a constituição de um campo para a ampliação da capacidade de interpretar e produzir sentidos em comum. Daí nossa aproximação com a hermenêutica filosófica, a partir do referencial de Gadamer (2007), bem como de autores contemporâneos, como Hermann (2002), Ruedell (2005 e 2007), Flickinger (2010), Palmer (2011), entre outros.

Corroborando os argumentos apresentados, e aproximando a discussão do contexto da formação de professores, Ruedell (2007, p.17) sinaliza para a possibilidade de pensar que "as práticas em sala de aula e todo o atual estado de discussão teórica sobre ensino e aprendizagem têm em sua base de sustentação uma discussão hermenêutica", mesmo que às vezes não percebamos isso.

Nessa direção, Hermann (2002) aborda as relações entre hermenêutica e educação, enfatizando que a hermenêutica possibilita à educação tornar-se esclarecida para si mesma acerca de seus próprios pilares de justificação, "por meio do debate a respeito das racionalidades que atuam no fazer pedagógico" (p. 83), proporcionando à educação a interpretação do seu modo de ser, em suas múltiplas faces. Diante disso, a autora expõe que a hermenêutica, a partir do momento que identifica uma dimensão criadora da compreensão, amplia o sentido da educação para além da normatividade técnico-científica.

Assim, o processo educativo extrapolaria a relação hegemônica sujeito-objeto, na qual há um sujeito que domina (ou se propõe a dominar) o objeto. Concordando com Paviani (2014), a interpretação hermenêutica põe em círculo o sujeito e o objeto, redimensionando suas representações de tal maneira, que aquele que interpreta algo, antes de tudo, interpreta a si mesmo. Com o pensamento nessa direção, Tardif (2014, p.103) aponta que:

O professor não é somente um "sujeito epistêmico" que se coloca diante do mundo numa relação estrita de conhecimento, que "processa" informações extraídas do "objeto" [...]. Ele é um "sujeito existencial" no verdadeiro sentido da tradição fenomenológica e hermenêutica, isto é, um "ser-no-mundo".

Nesse sentido, Gadamer (2005) defende uma abertura da experiência educativa, entendendo a posição do aluno como a de alguém que necessita realizar sua própria experiência, possibilitando a ampliação do conhecimento do que está sendo vivenciado. Assim, é importante que o aluno aprenda a reconhecer seus limites, esforço que não só o torna mais humilde, como também o potencializa para aprender sobre aquilo que ainda não compreende. Neste caso, a hermenêutica, concordando com Paviani (2014), recupera e revitaliza a audição do outro como pressuposto para a produção de sentidos em comum, algo imprescindível para a formação de professores. 
Para tal, Gadamer (2007) trabalha com a noção de "fusão de horizontes", na qual um horizonte não significa uma fronteira rígida, mas algo que nos acompanha conforme nosso avanço. Essa expressão possibilita que cada sujeito observe o mundo através de um horizonte e, na busca de estabelecer um entendimento com os outros sujeitos, esses horizontes recuam ou avançam, transformando a maneira como o sujeito se relaciona consigo mesmo e com o mundo ${ }^{5}$.

Assim, a ação educativa, através de uma reflexão hermenêutica, implica a compreensão de algo ou alguém, produzindo, antes de tudo, uma autocrítica. Aquele que compreende não adota uma atitude de superioridade, mas permite um exame de sua suposta verdade, de seus próprios preconceitos. Isso só ocorre no espaço do diálogo, possibilitando uma ação crítica sobre si mesmo (HERMANN, 2002), esforço nada fácil em se tratando da formação de professores. Para Hermann (2002, p.86),

A experiência educativa, enquanto hermenêutica, exige a exposição ao risco, às situações abertas e inesperadas, coincidindo com a impossibilidade de assegurar a tais práticas educativas uma estrutura estável, que garanta o êxito da ação interventiva.

Quando falamos de hermenêutica na educação, especificamente no caso deste ensaio, na formação de professores, não se pode deixar de reconhecer a experiência do estranhamento, que causa a desorientação e a desestabilização, provocando uma quebra da regularidade metódica e uma ruptura com as situações vivenciadas cotidianamente. Segundo Dalbosco (2014, p. 1047), "aprendemos muito de nós mesmos ao levarmos a sério o processo de estranhamento que o olhar do outro nos provoca". Assim, o processo formativo requer a capacidade de ouvir o outro, ou seja, a observação transforma-se em escuta, e saber observar significava saber ouvir.

Temos também a experiência do conhecer, que ocorre no diálogo, "que implica o deslocamento da possibilidade de chegar ao conhecimento por uma ação da consciência do sujeito para dar relevância à conversação" (HERMANN, 2002, p. 90). Dessa forma, aprender realiza-se por intermédio do diálogo, tornando explícita a relação entre compreender, aprender e dialogar.

O diálogo consiste na possibilidade de experimentar nossa singularidade e a experiência do outro com suas negações e aprovações. Isso só ocorre quando o diálogo nos "deixa" algo. Segundo Gadamer (2005, p. 247), o diálogo não é a experiência de algo novo, mas sim "algo outro que veio ao nosso encontro que ainda não havíamos encontrado em nossa própria experiência do mundo". Assim, o diálogo tem uma força transformadora por princípio, pois, se bem-sucedido, algo "fica em nós", algo que nos transforma, de imediato ou com o tempo, representando o que podemos denominar de uma experiência genuína de mundo.

As palavras presentes no diálogo, juntas, representam um conjunto de um processo de pergunta e resposta, significando o que está sendo dito e ouvido. As palavras também questionam, configuram identidades e apontam diferenças, dando sentido ao diálogo. Gadamer (2005) afirma que aprendemos pelo diálogo, pois, nesse processo, o sujeito se educa com o outro. E, em um diálogo verdadeiro, nenhum dos indivíduos tem posição superior ao outro.

No diálogo, Dalbosco (2014) aponta para a compreensão do outro, não o aniquilando, mas deixando em aberto a possibilidade de ouvir a outra pessoa. $\mathrm{O}$ autor também ressalta a

\footnotetext{
${ }^{5}$ Um horizonte, segundo Gadamer (2007), se desloca conosco conforme nosso avanço, convidando-nos a seguir adentrando, movendo-se junto. Lawn (2007) lembra que se trata de um termo usado inicialmente por Nietzsche e Husserl para se referir a determinado ponto de vista ou perspectiva do mundo. Gadamer o entende como o alcance da visão que inclui tudo que pode ser visto, a partir de uma determinada perspectiva de mundo. Nessa direção, a "fusão de horizontes" é uma expressão importante, que descreve a possibilidade do entendimento.
} 
historicidade que a relação entre os sujeitos comporta, "como nenhum dos sujeitos envolvidos possui a última palavra, a luta por reconhecimento recíproco é constante e os consensos que resultam daí são provisórios" (p.1046). Nesse sentido, levar-se e levar o outro a sério exige estar aberto, ouvindo mutuamente, o que é a base para o diálogo, pressuposto importante para o diálogo.

Hermann (2002, p. 95) afirma que, através do diálogo, há uma abertura de horizontes que possibilita à educação "fazer valer a polissemia dos discursos e criar um espaço de compreensão mútua entre os envolvidos". Assim, a educação é o lugar do diálogo, da palavra e da reflexão, ultrapassando os conhecimentos, conduzindo-nos à formação pessoal, bem como produzindo diferentes formas de objetividade, construídas pelo diálogo, esforço alicerçado em referências intersubjetivas.

Para ampliar essa discussão, Menezes (2013) apresenta a hermenêutica filosófica como uma possibilidade de contraposição ao modelo dominante científico-metodológico como única forma na construção do conhecimento, resgatando o ato de interpretar e produzir sentido dos sujeitos como balizador para as relações entre humanos. O autor cita Gadamer para afirmar que a hermenêutica, ao caracterizar-se como jogo filosófico e pedagógico, possibilita superar o reducionismo da ciência moderna em mero controle de metodologias científicas. Pois, através de uma perspectiva da hermenêutica, a educação

Abre um modo de filosofar e educar que problematiza a compreensão da experiência humana no mundo, um mundo que desde já se oferece interpretado. Por isso, o seu problema central é mostrar que a verdade, enquanto jogo (experiência e vivência), é interpretação, é um ato histórico-cultural: um acontecer efeitual (MENEZES, 2013 p. 63).

Nesse sentindo, a formação de professores em diálogo com a hermenêutica desenvolve uma compreensão ao sentido do saber cultural, promovido sempre na intersubjetividade entre sujeitos. Compreender uma abordagem hermenêutica da educação revê a formação humana como um conceito histórico, constituindo um elemento essencial para as ciências humanas.

Dessa maneira, a formação de professores é um espaço de abertura e do reconhecimento de outros sujeitos, possibilitando dar sentido àquilo que vem de fora de nós, compreendendo o outro e o saber cultural produzido historicamente. A partir dessas reflexões de fundo, abordaremos a seguir algumas aproximações entre a hermenêutica e a formação de professores especificamente no campo da EF, tema proposto no inicio deste texto.

\section{Um olhar hermenêutico na formação de professores no campo da educação física...}

É possível inferir que a EF contemporânea se constitui de diferentes subcampos que vêm enfrentando dificuldades para o diálogo entre si, evidenciando um movimento de disputa política e epistemológica entre diferentes "Educações Físicas". Nesse caso, a disputa interna, a desigualdade nas relações de poder e/ou o desinteresse por outros saberes são algumas das possíveis razões para essa configuração contemporânea do campo - certamente, esforços na direção contrária desse argumento vêm se avolumando nos últimos dez anos, ainda sem a devida densidade.

Este cenário, sem dúvidas, se reflete no processo de formação de professores que acaba assumindo como referência diferentes subcampos da EF na edificação de propostas curriculares. Para tais argumentos, cabe destacar que os processos de formação de professores de EF são constituídos, em maior ou menor medida, por diferentes "Educações Físicas", que acabam se constituindo como referências para o trabalho de futuros professores.

Para lidar melhor com tal diversidade, no âmbito da formação inicial, visualizamos no diálogo um caminho para a construção de novos sentidos, considerando um esforço herme- 
nêutico de interpretação que permita conviver melhor com diferentes formas de interpretar fenômenos relativos à EF. Assim, esse olhar hermenêutico apresenta-se como uma possibilidade para que as diferentes comunidades científicas e políticas constituídas nesse âmbito possam minimante considerar a lógica com que seus projetos são edificados, sem perder de vista suas especificidades.

Para Fensterseifer (2009), a busca pela legitimação da EF se configura a partir da própria maneira com que lidamos ao produzir conhecimento - e como esse conhecimento se coloca na condição de conhecimento válido em processos de formação docente. Diante de questões como estas, entendemos a hermenêutica como uma possibilidade para pensarmos o que o autor denomina de "responsabilidade pedagógica da Educação Física" (p. 252). Para tanto, destaca que a

Hermenêutica não descarta a pretensão de objetividade das ciências (naturais ou humanas), mas não tem ilusões de que elas esgotem o sentido dos temas/objetos sobre os quais anuncia suas conclusões. Reconhece no método científico um potencial explicativo e funcional extremamente engenhoso, porém, não ignora que suas possibilidades são parciais, e nisso não vai nenhum demérito (FENSTERSEIFER, 2009, p. 253).

Assim, a hermenêutica pode ser entendida como um princípio transformador para o campo da EF, que se refere ao sentido da interpretação das diferentes produções que emergem desse campo, como forma de possibilitar a autonomia diante dessa diversidade. Ou seja, compreender o movimento político e epistemológico do campo da EF requer uma leitura panorâmica e crítica do campo, menos sectária e mais aberta ao diferente, ao distinto, ou seja, às peculiaridades da EF. Dessa forma, assumindo uma postura gadameriana, visualizamos a formação de professores de EF como um processo de construção de diálogos entre os sujeitos que representam essas diferentes "Educações Físicas", o que permitiria a edificação de sínteses, derivadas de distintos horizontes, na qual a fusão entre eles permitiria a abertura de novas e maiores perspectivas para propostas de formação de professores nesse campo.

Para tal, mais do que "defender" uma comunidade ou outra, o desafio maior é compreender como elas se constituem, a lógica como operam, bem como seu projeto para o campo e os mecanismos que possibilitam sua "influência" em propostas de formação. Se entendermos a formação de professores como um processo de busca de autonomia, de aprender a pensar por si, sem a direção de outrem, respondendo com responsabilidade pelas escolhas feitas, reconhecemos a importância de uma visão panorâmica sobre as diferentes "Educações Físicas" como uma responsabilidade inalienável de propostas críticas de formação docente. Nesse sentido, mais que a "filiação" a um determinado subcampo, reconhecemos a importância de fomentar, no futuro professor, o desejo de conhecer mais sobre o campo específico da EF, em suas múltiplas dimensões, bem como suas conexões com outros campos do conhecimento. $\mathrm{O}$ trabalho docente nos processos de formação de professores se apresenta, então, no sentido de ampliar os horizontes, sem assumir uma formação estreita, especializada precocemente.

Nesse sentido, pensar um olhar hermenêutico sobre a formação docente em EF não se trata de pouca coisa, pois instiga a construção de horizontes interpretativos acerca de si mesmo, do outro e do mundo, compartilhando saberes entre os sujeitos, ao mesmo tempo em que estimula um olhar sobre os significados de ser professor e do ato de ensinar. Assim, se torna um grande desafio na formação de professores de EF possibilitar ao estudante uma compreensão alargada do campo de conhecimento da EF, no qual possa ser atribuído um estatuto epistemológico capaz de romper com um processo que o reduz a uma atividade prática meramente instrumental.

Berticelli (2004, p.297) sinaliza, a partir de um referencial hermenêutico, o trabalho docente como condutor de um campo de liberdade do fazer educativo, que "nos afasta de 
pressupostos dogmáticos e fundacionalistas por princípio. Esta é uma condição atrativa e motivadora ante as demandas de novas formas de entender o conhecimento em nosso tempo". Ou seja, assumir a hermenêutica como referência se coloca na contramão de fomentar dogmas e pensamentos preconcebidos ou, ainda, a existência de uma "verdade" que oblitere outras leituras de mundo. Concordando com Gadamer (2001), a hermenêutica representa, na contemporaneidade, um caminho para pensar por si, sem desconsiderar aspectos de ordem macro. Neste caso, a maiêutica, de tipo socrático, tal como referido por Paviani (2014), se coloca na condição de horizonte privilegiado como meio de ampliação da capacidade de professor e aluno conduzirem-se na direção de produzir sentidos em comum, tomando o jogo de pergunta e resposta como referência no cotidiano da formação.

Nessa direção, a docência em EF pode ser compreendida como um jogo de pergunta e resposta, considerando a noção dialética da pergunta e da resposta fundamentada em Gadamer (2007). O ponto de partida é a pergunta que coloca o sujeito em um horizonte amplo, sendo que a resposta não está determinada a priori por nenhuma entidade supra-humana, mas se edifica na medida em que passa a fazer sentido para os envolvidos. Compreender, orientado pelo horizonte da pergunta, é compreendê-la no momento em que os sujeitos compartilham do mesmo horizonte. Assim, o círculo hermenêutico, pelo diálogo da pergunta e da resposta, como se refere Berticelli (2004), nos leva à complexidade da epistemologia, esforço necessário para compreender o conhecimento implicado e pertinente à formação de professores no campo da EF.

Nessa discussão, as relações entre professor e aluno e entre estes e o conhecimento adquirem um "novo status", mais fluído e móvel, que se demonstra, ao mesmo tempo, como uma situação nova a cada instante. Aqui, a fluidez do próprio campo da EF permite entender a multidimensionalidade na produção do conhecimento, aspecto que impacta a formação de professores. Ainda permite compreender que a busca de conhecimento é sempre uma busca de sentidos, como afirma Berticelli (2004).

Assim, pensar na intervenção do professor e no conhecimento a ser tratado é um processo que necessita de negociações e de uma disposição de olhar na mesma direção, tanto do professor como do aluno, esforço nada fácil que permeia toda a relação pedagógica. Nesse caso, reconhecer que a intervenção pedagógica se dá com outros sujeitos e não sobre outros sujeitos e que o encontro entre professor e aluno e seus diferentes mundos permite uma ampliação da janela pela qual ambos veem seus próprios mundos, ampliando a própria compreensão construída pela tradição (polissêmica) do campo da EF.

Porém, o encontro entre diferentes horizontes e o processo de produção de sentidos na formação de professores nunca são alcançados inteiramente, pois entre o que o professor fala e o que o aluno escuta (ou vice-versa) há uma lacuna, um mundo de distância. É nesse ponto que entendemos como um dos objetivos principais do trabalho docente, num curso de formação de professores de EF, diminuir essa distância entre os mundos do professor e do aluno, através da construção de sentidos em comum aos sujeitos constituintes desse cenário.

Com essa postura, não há como repetir matéria nas aulas, mesmo considerando os conceitos já existentes do conteúdo proposto, pois há uma confluência de sentidos que precisa acontecer em diversos momentos, que poderá ocasionar um abrir e fechar caminhos, certas vezes tão rápido que obriga o professor a se manter vigilante sobre aquilo que se desenrola em sala de aula. Assim, interpretar e compreender o que aparece na aula deve ser levado a sério, pois esta é sempre um acontecimento que não se repete.

Pensar a hermenêutica como um princípio transformador representa uma postura de suma relevância no trabalho docente na formação de professores de EF, pois a riqueza que o movimento hermenêutico proporciona gera sempre novas janelas para o mundo, o que permite a construção de novos sentidos e significados acerca da EF, do trabalho docente nesse campo, bem como das responsabilidades do processo de formação de professores. 
Portanto, uma orientação hermenêutica para o campo da EF poderia permitir aos professores e estudantes uma maior capacidade de percepção diante da diversidade na qual esse campo se edifica, sem a necessidade de "escolher" (muitas vezes, sem conhecer) aquilo que mais agrada ou convence. Dessa forma, a hermenêutica poderia ampliar a capacidade dos discentes e docentes de lidarem com o diferente, a fim de ampliar possibilidades dialógicas como um princípio ético de docência e do aprender a ser professor. Amplia-se também, com esse referencial, a estrutura de referências que orientam as discussões da EF, partindo da suposição de que a constituição de verdades ocorre por produção de sentidos em contextos coletivos. Levar essa discussão para a formação de professores de EF representa esforço complexo, na medida em que abrimos mão do conforto dos dogmas e pensamentos preconcebidos e mergulhamos na possibilidade de inflexão sobre o conhecimento que entendemos como pertinente para constituir processos de formação docente no campo da EF.

\section{Considerações finais}

Pensar na formação de professores no campo da EF a partir de um referencial hermenêutico pressupõe refletir sobre o sentido da formação para além de uma compreensão técnico-científica, como um processo educacional ampliado, em que a experiência do professor e do aluno aconteça no e pelo diálogo.

Diante disto, é necessária a reflexão sobre as escolhas epistemológicas e políticas que se desdobram em conteúdos, metodologias e modos de avaliação utilizados pelos docentes em processos de formação de professores. Muitas vezes, se aliam e representam uma síntese pouco pensada, que acaba por reduzir o espaço do acontecimento da experiência, tanto do professor como do aluno (em certos casos, sem a consciência desse reducionismo). Considerar o referencial de Gadamer (2007) representa uma possibilidade para o professor compreender o aluno como sujeito que tem limites e capacidades que devem ser respeitados, possibilitando assim a ampliação do conhecimento através da experiência. Da mesma forma, cabe ao professor tensionar esses limites, potencializando as capacidades do aluno de compreender de forma crítica a conjuntura contemporânea da EF (historicamente produzida), bem como constituir experiências de conhecimento, outra possibilidade significativa que se abre a partir de aproximações com o referencial hermenêutico ora proposto.

Entender a formação de professores como espaço e tempo de experiência possibilita, entre docente e discente, o diálogo, que ocorre através da conversação entre sujeitos. Assim, o diálogo permite a compreensão e o aprendizado sobre como funciona o mundo, em um eterno "de novo", como se fosse, sempre, a "primeira vez". Podemos considerar, então, que o diálogo também proporciona aos sujeitos envolvidos a troca de conhecimentos diferentes e divergentes, respeitando a diversidade de posições, sem absolutizá-las nem relativizá-las, conduzindo a uma fusão de horizontes, o que permite considerar distintas perspectivas através de novos horizontes que se abrem.

Dessa maneira, a hermenêutica possibilita à formação humana compreender o sentido do saber cultural produzido pela história, esforço imprescindível para a formação de professores. Com isso, compreender que esse saber produzido no/pelo campo da EF não é monolítico, mas fluido, multidimensional, constituído por diferentes epistemologias, interesses e jogos de poder que se enredam em distintas propostas de formação docente.

Através desse processo, é possível aprimorar nossa capacidade de reconhecer e lidar com as diferenças conceituais do próprio campo, ao significar aquilo que está presente em nosso entorno, podendo compreender o outro e os saberes existentes, neste caso, no interior do campo da EF e em suas relações com outros saberes e outras dimensões de mundo.

Levar esta discussão para a formação de professores de EF, considerando as manifestações da cultura corporal de movimento com as quais nos aproximamos na condição de pro- 
fessores, eleva nossas possibilidades de lidar com fenômenos que jogam conosco, que também nos subtraem a condição de sujeitos, que nos arrebatam de tal forma que nos transformam, tais como o esporte, o jogo, a dança, entre outros. Mergulhar na profundidade dessa assertiva representa um desafio para pensar o esporte, a dança, o jogo, bem como nossa compreensão acerca desses fenômenos e os referenciais com os quais nos fundamentamos para atuar em processos de formação de professores, na condição de professores que ensinam estudantes a serem professores. Talvez aí, no reconhecimento dessa síntese conclusiva, resida uma possibilidade de ampliação dos trabalhos de natureza hermenêutica no campo da EF brasileira.

\title{
TEACHER EDUCATION AND HERMENEUTICS: REFLECTIONS FOR THE FIELD OF PHYSICAL EDUCATION...
}

\begin{abstract}
This paper aims to address approaches between teacher education and hermeneutics, in the direction of promoting reflections in the field of Physical Education (PE). To do this, first, we present a brief understanding of hermeneutics. Next, we address the issue of hermeneutics in the teacher education process and specifically in the field of PE. We conclude that take seriously this discussion at PE teacher education is complex effort, as we open up the comfort of made dogmas and thoughts, and plunged into the possibility of turning on the different knowledge that can be a teacher education process field PE.

Keywords: Physical Education. Hermeneutics. College Education.

\section{FORMACIÓN DE DOCENTES Y HERMENÉUTICA: REFLEXIONES PARA EL CAMPO DE LA EDUCACIÓN FÍSICA...}

\section{Resumen}

Este texto tiene como objetivo analizar las aproximaciones entre la formación docente y la hermenéutica, con la finalidad de promover una reflexión en el campo de la educación física (EF). Para eso, en primer lugar, se presenta una breve comprensión de la hermenéutica. A continuación, nos centramos en el tema de la hermenéutica del proceso de formación docente, específicamente en el campo de la EF. Llegamos a la conclusión de que tomar en serio la discusión sobre la formación de profesores de EF es un esfuerzo complejo, ya que nos apartamos de la comodidad de los dogmas y pensamientos preconcebidos, y concentramos nuestra atención en la posibilidad de inflexión acerca de conocimientos diferentes, que pueden construir el proceso de formación de los profesores no campo de la EF.

Palabras clave: Educación Física. Hermenéutica. Educación Universitaria.

\section{Referências}

ALMEIDA, F.Q.; BRACHT, V.; VAZ, A. F. Classificações epistemológicas na educação física: redescrições... Movimento, Porto Alegre, v. 18, n. 4, p. 241-263, out/dez de 2012. 
BERTICELLI, I. A. A origem normativa da prática educacional na linguagem. Ijuí: UNIJUÍ, 2004.

DALBOSCO, C. A. Pesquisa educacional e experiência humana na perspectiva hermenêutica. Cadernos de Pesquisa, v. 44, n. 154, p. 1028-1051, out./dez. 2014.

FENSTERSEIFER, P. E. Linguagem, hermenêutica e atividade epistemológica na Educação Física. Movimento, Porto Alegre, v. 15, n. 4, p. 243-256, outubro/dezembro de 2009.

Educação Física: atividade epistemológica e objetivismo. Filosofia e Educação: Revista Digital do Paideia, Campinas, v. 2, n. 2, p. 99-110, out. 2010.

FLICKINGER, H-G. A caminho de uma pedagogia hermenêutica. Campinas (SP): Autores Associados, 2010.

GADAMER, H. Verdade e método I: traços fundamentais de uma hermenêutica filosófica. 8. ed. Petrópolis: Vozes; Bragança Paulista: São Francisco, 2007.

. Verdade e método II: complementos e índices. 2 ed. Petrópolis: Vozes; Bragança Paulista: São Francisco, 2005.

. Uma conversa com Gadamer. Entrevista realizada por Raquel Abi-Sâmara. UERJ, 2001. Disponível em: <http://www.apario.com.br/forumdeutsch/revistas/vo19/umaconversacomgadamer.pdf> Acesso em: 13 mar. 2015.

HERMANN, N. Hermenêutica e educação. Rio de Janeiro: DP\&A, 2002.

LAWN, C. Compreender Gadamer. Petrópolis: Vozes, 2007.

MENEZES, N. C. R. Pensamento complexo e hermenêutica filosófica: o ser docente. 2013. Dissertação (Mestrado) - Universidade do Oeste de Santa Catarina, Joaçaba, 2013.

PALMER, R. E. Hermenêutica. Lisboa: Edições 70, 2011.

PAVIANI, J.. A pedagogia hermenêutica de Hans-Georg Flickinger. In: BOMBASSARO, Luiz Carlos; DALBOSCO, Cláudio Almir; HERMANN, Nadja. (Org.). Percursos hermenêuticos e políticos: homenagem a Hans-Georg Flickinger. Ied.Porto Alegre: EDIPUC-RS, 2014, v. 1, p. 106-.

RUEDELL, A. Hermenêutica. In: GONZÁLEZ, F. J.; FENSTERSEIFER, P. E. (Org.). Dicionário crítico de Educação Física. Ijuí: Unijuí, 2005. p. 223-227.

Hermenêutica e ensino. In: POMMER, A.; FRAGA, P. D.; SCHNEIDER, P. R. (Org.). Filosofia e crítica. Festschrift dos 50 anos do curso de filosofia da Unijuí. Ijuí: Unijuí, 2007.

TARDIF, M. Os saberes docentes e formação profissional. 16. ed. Petrópolis: Vozes, 2014. 
Revisado em: 28/11/2016

Aprovado em: 17/04/2017

Endereço para correspondência:

angelicamadela@unochapeco.edu.br

Angelica Madela

Universidade Comunitária da Região de Chapecó

Avenida Senador Attílio Fontana

591-E - Efapi, Chapecó - SC

89809-000 